\title{
LETTER
}

\section{Imbalanced pro- and anti-Th17 responses (IL-17/granulocyte colony-stimulating factor) predict fatal outcome in 2009 pandemic influenza}

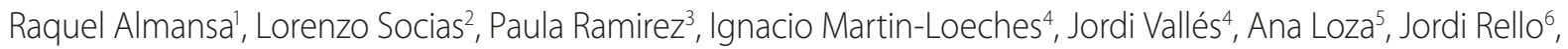 \\ David J Kelvin7, Cristobal León ${ }^{5}$, Jesús Blanco ${ }^{8}$, David Andaluz ${ }^{9}$, Dariela Micheloud ${ }^{10}$, Enrique Maraví1", \\ Raul Ortiz de Lejarazu' and Jesus F Bermejo-Martin*
}

Several clinical studies have confirmed an association between persistent hypercytokinemia and severe 2009 pandemic influenza, but none of these have used predictive models to analyze the relationship between the cytokines involved and disease outcome [1-4].

In the present work, we re-analyzed the results from two cohorts of critically ill patients suffering from pandemic influenza infection in 2009 [1,2]. Thirty-five critically ill patients hospitalized with primary viral pneumonia were included in the analysis.

The levels of 27 cytokines in peripheral blood measured during the first 24 hours following admission to the hospital were included in a Cox regression analysis to evaluate their association with mortality at 28 days. This analysis was adjusted by APACHE II score and the presence/absence of mechanical ventilation in order to preclude their potential influence on the results. IL-6, IL-8, IL-7, IL-17, and granulocyte colony-stimulating factor (G-CSF) yielded $P$-values $<0.2$ in the univariate analysis. In the multivariate analysis, high IL-17 levels were associated with increased probability of survival, while high levels of G-CSF were associated with increased risk of mortality at 28 days $(P<0.05$; Figure 1$)$. Kaplan Meier curves confirmed the association of IL-17 with survival and of G-CSF with occurrence of earlier death (Figure 1). Patients who died had significantly higher levels of G-CSF than those who survived (mean (standard deviation) pg/ml: 6,709.4 (17,979.1) and 2,043.9 (7,362.7), respectively; Mann Whitney $U$ test); in contrast, surviving patients had higher levels of IL-17

${ }^{*}$ Correspondence: jfbermejo@saludcastillayleon.es

IInfection and Immunity Medical Investigation Unit (IMI), Microbiology and Immunology Service Hospital Clínico Universitario-IECSCYL, Avda Ramón y Cajal 3, 47005 Valladolid, Spain

Full list of author information is available at the end of the article than those who died (mean (standard deviation) $\mathrm{pg} / \mathrm{ml}$ : 7.7 (8.1) and 1.5 (0.3), respectively; Mann Whitney U test).

A beneficial role of IL-17 in lethal influenza has been previously proposed [3]. In our experience, 9 out of the 10 patients who died had undetectable levels of IL-17. G-CSF is the principal cytokine controlling neutrophil development and function and could thus mediate excessive recruitment of neutrophils to the lungs, contributing to impairment of the respiratory system. In turn, G-CSF induces overexpression of negative regulators of Th17 differentiation [5]. In fact, G-CSF levels correlated negatively with IL-17 levels in our cohort, supporting a potential inhibitory role of G-CSF on the secretion of IL-17 in these patients (Spearman $\mathrm{r}$ coefficient, -0.43 ; $P$-value 0.010 ).

In conclusion, IL-17 has been shown to be protective in severe pandemic influenza, while G-CSF is a risk factor for mortality, indicating the existence of imbalanced proand anti-Th17 responses during this disease.

\section{Abbreviations}

G-CSF, granulocyte colony-stimulating factor; IL, interleukin.

\section{Competing interests}

The authors declare that they have no competing interests.

\section{Authors' contributions}

RA, ROL, DJK, IML, and JFBM assisted in the design of the study, coordinated patient recruitment, analyzed and interpreted the data, and assisted in writing the paper. $L S, P R, A L, J R, C L, J B, D A, D M, E M$, and JV recruited the patients, assisted in the analysis, interpretation of data, and writing the report.

\section{Acknowledgments}

This work has been conducted by an international team pertaining to the Spanish-Canadian Consortium for the Study of Influenza Immunopathogenesis. The authors would like to thank also the nursing teams who kindly collected the samples and Lucia Rico and Veronica Iglesias for their precious laboratory assistance. The study was scientifically sponsored by the Spanish Society for Critical Care Medicine (SEMICYUC). Funding: Ministerio de Ciencia, MICCIN-FIS/JCYL-IECSCYL-SACYL (Spain); Programa de Investigación Comisionada en Gripe, GR09/0021-EMER07/050- PI081236-RD07/0067; National Institutes of Health (NIH), University Health Network and IDR Canada (DJK). 

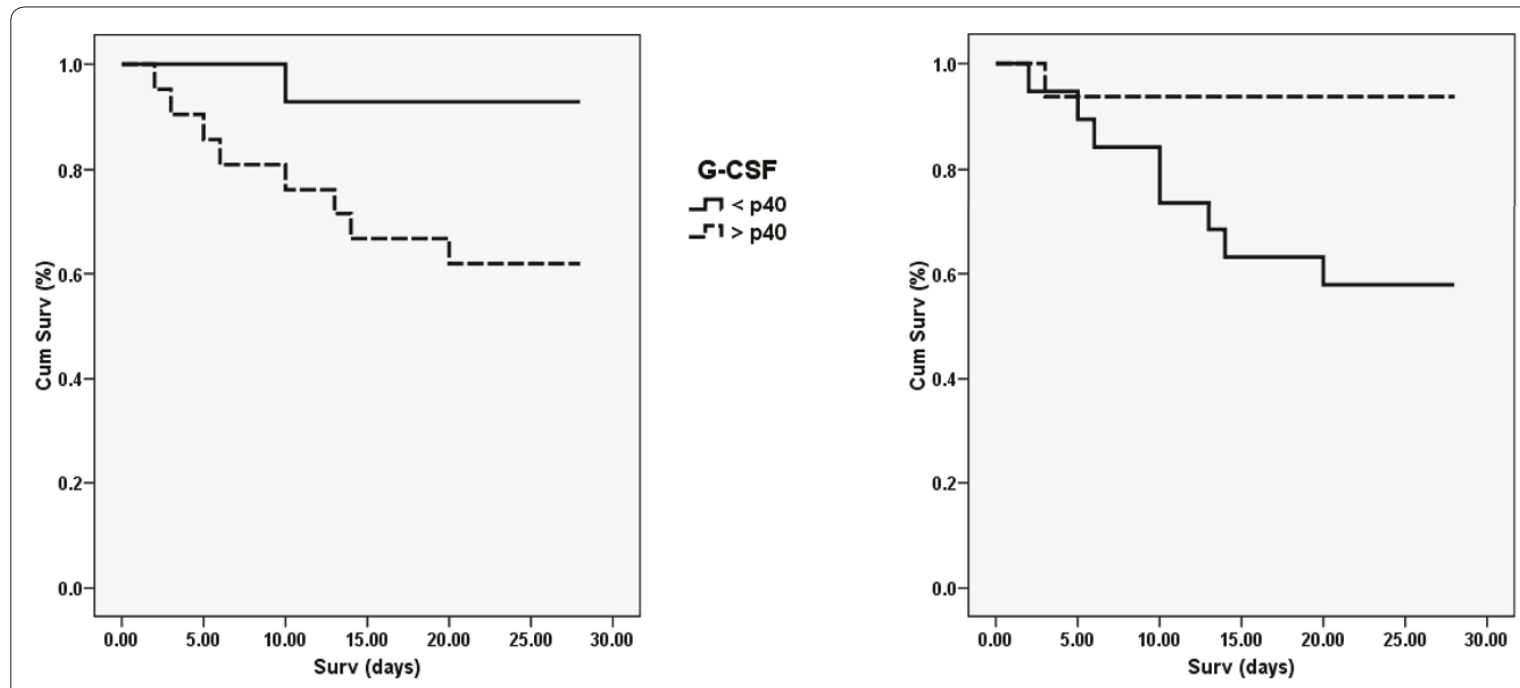

\begin{tabular}{|c|c|c|c|c|}
\hline & $\begin{array}{c}\text { Un-adjusted } \\
\text { HR [95\%CI] }\end{array}$ & $\boldsymbol{p}$ & $\begin{array}{c}\text { Adjusted } \\
\text { HR [95\%CI] }\end{array}$ & $\boldsymbol{p}$ \\
\hline G-CSF & $1.59[0.97-2.61]$ & 0.061 & $1.94[1.10-3.42]$ & 0.023 \\
\hline IL-17 & $0.15[0.02-1.10]$ & 0.063 & $0.01[0.00-0.62]$ & 0.030 \\
\hline
\end{tabular}

Figure 1. Risk of death based upon G-CSF and IL-17 levels. Top panels: Kaplan-Meier curves showing cumulative survival versus survival. Deciles of cytokine concentrations in plasma (pg/ml) were calculated and used to compare survival time in patients with low (solid line) and high cytokine levels (dashed line). The first decile showing significant differences between groups is represented (40th percentile). Groups were compared by the log-rank test (Mantel-Haenzel). Data collection ended at day 28. Bottom panel: Cox regression analysis for mortality adjusted by APACHE II score and the presence/absence of mechanical ventilation. Logarithmic concentrations of the cytokines were used in the regression analysis to satisfy the linearity assumption. Cl, confidence interval; G-CSF, granulocyte colony-stimulating factor; HR, hazard ratio.

\section{Author details}

'Infection and Immunity Medical Investigation Unit (IMI), Microbiology and Immunology Service Hospital Clínico Universitario-IECSCYL, Avda Ramón y Cajal 3, 47005 Valladolid, Spain. ${ }^{2}$ Critical Care Department, Hospital Son LlatzerSEMICYUC, Ctra. Manacor, km 4, 07198 Palma de Mallorca, Spain. ${ }^{3}$ Critical Care Department, Hospital Universitario La Fe- SEMICYUC, Valencia, Avda Campanar 21, 46009, Spain. ${ }^{4}$ Critical Care Centre Parc Tauli, Sabadell University Hospital, Sabadell, Spain. ${ }^{5}$ Critical Care Department, Hospital Universitario de Valme SEMICYUC, Carretera de Cádiz s/n 41014 Sevilla, Spain. ${ }^{6}$ Critical Care Department, area General, Hospital Vall d'Hebron, Institut de Recerca Vall d'Hebron-UAB, CIBERES- SEMICYUC, Paseo Vall d'Hebron, 119-129, 08035, Barcelona, Spain. ${ }^{7}$ University Health Network, Toronto Medical Discovery Tower, 3rd floor Room 913, 101 College Street, Toronto, ON M5G 1L7, Canada. ${ }^{8}$ Critical Care Department, Hospital Universitario Rio Hortega-SACYLSEMICYUC and CIBER de Enfermedades Respiratorias (Instituto de Salud Carlos III), C/Dulzaina № 247012 Valladolid, Spain. ${ }^{\circ}$ Critical Care Department, Hospital Clínico Universitario-SACYL/SEMICYUC, Avda Ramón y Cajal 3, 47005 Valladolid, Spain. ${ }^{10}$ ntensive Care Unit and Internal Medicine Service, Hospital Gregorio Marañón, C/Doctor Esquerdo 46, Madrid, 28007, Spain. " ${ }^{1 C}$ ritical Care Department, Hospital Virgen del Camino- SEMICYUC, C/ de Irunlarrea 4, 31008 Pamplona, Spain.

\section{Published: 20 October 2011}

\section{References}

1. Bermejo-Martin JF, Ortiz de Lejarazu R, Pumarola T, Rello J, Almansa R, Ramírez P, Martin-Loeches I, Varillas D, Gallegos MC, Serón C, Micheloud D, Gomez JM, Tenorio-Abreu A, Ramos MJ, Molina ML, Huidobro S, Sanchez E, Gordón M,
Fernández V, Del Castillo A, Marcos MA, Villanueva B, López CJ, RodríguezDomínguez M, Galan JC, Cantón R, Lietor A, Rojo S, Eiros JM, Hinojosa C, et al. Th1 and Th17 hypercytokinemia as early host response signature in severe pandemic influenza. Crit Care 2009, 13:R201.

2. Bermejo-Martin JF, Martin-Loeches I, Rello J, Antón A, Almansa R, Xu L, LopezCampos G, Pumarola T, Ran L, Ramirez P, Banner D, Ng DC, Socias L, Loza A, Andaluz D, Maravi E, Gómez-Sánchez MJ, Gordón M, Gallegos MC, Fernandez V, Aldunate S, León C, Merino P, Blanco J, Martin-Sanchez F, Rico L, Varillas D, Iglesias V, Marcos MÁ, Gandía F, et al:: Host adaptive immunity deficiency in severe pandemic influenza. Crit Care 2010, 14:R167.

3. To KK, Hung IF, Li IW, Lee KL, Koo CK, Yan WW, Liu R, Ho KY, Chu KH, Watt CL, Luk WK, Lai KY, Chow FL, MokT, Buckley T, Chan JF, Wong SS, Zheng B, Chen $\mathrm{H}$, Lau CC, Tse H, Cheng VC, Chan KH, Yuen KY: Delayed clearance of viral load and marked cytokine activation in severe cases of pandemic $\mathrm{H} 1 \mathrm{~N} 1$ 2009 influenza virus infection. Clin Infect Dis 2010, 50:850-859.

4. Hagau N, Slavcovici A, Gonganau DN, Oltean S, Dirzu DS, Brezoszki ES, Maxim M, Ciuce C, Mlesnite M, Gavrus RL, Laslo C, Hagau R, Petrescu M, Studnicska DM: Clinical aspects and cytokines response in severe H1N1 influenza A virus infection. Crit Care 2010, 14:R203.

5. Toha HC SL, Soea Y, WuC Y, Phoona YP, Chia WK, WuC J, Wonge KY, Tand P: G-CSF induces a potentially tolerant gene and immunophenotype profile in T cells in vivo. Clin Immunol 2009, 132:83-92.

\section{doi:10.1186/cc10426}

Cite this article as: Almansa R, et al.: Imbalanced pro- and anti-Th17 responses (IL-17/granulocyte colony-stimulating factor) predict fatal outcome in 2009 pandemic influenza. Critical Care 2011, 15:448. 